\title{
Revision arthroplasty: an update
}

\author{
D. Williams • A. Taylor $\cdot$ P. McLardy-Smith
}

Published online: 24 August 2009

(C) ISS 2009

\section{Introduction}

Major joint arthroplasty is undoubtedly one of the surgical success stories of the 20th century. The number of primary and revision hip and knee replacements performed each year has increased exponentially over the last half century: 6 total hip replacements (THRs) were performed in Sweden in 1967 ; by 2005 there were 13,822 . These increases have been sustained over the first 5 years of the new millennium: numbers are up between 6 and 21\% for primary THR and up between 4 and $26 \%$ for revision hip surgery. Total knee replacement (TKR) has seen similar increases: up between 16 and $44 \%$ for primary TKR and up between 25 and $29 \%$ for revision knee surgery over the same period [1-3].

Phillip Wiles designed and implanted the first prototype hip replacements back in the 1930s. These produced initial relief of pain, but quickly loosened and failed. During the early 1950s, John Charnley introduced a Teflon hip resurfacing that wore out within 2 years. That design was superseded by a cemented stem with a metal head articulating against a Teflon socket that again produced severe osteolysis and loosening $[4,5]$. Larger femoral heads in this series of patients showed higher volumetric polymer wear; therefore, smaller $(22.25-\mathrm{mm})$ femoral heads were used in future designs [6]. The smaller head did, however, produce greater linear penetration into the polymer cup and was less stable.

By 1962, a high-density polyethylene cup combined with the cemented femoral stem (and the 22.25-mm femoral head) was being used with success in the elderly inactive

D. Williams $(\bowtie) \cdot$ A. Taylor $\cdot$ P. McLardy-Smith

Hip and Knee Arthroplasty Team, Nuffield Orthopaedic Centre, Oxford, OX3 7LD, UK

e-mail: danhwilliams@hotmail.com population [7]. This design and combination of materials has formed the basis of future developments. Charnley recognised, however, that its success would largely depend on the rate and effect of polyethylene wear and cautioned against the use of hip replacement in younger patients: "In this age group we look for factors which offer a 'built-in restraint' which will continue after the operation, such as defective knees or ankles". He understood that younger patients with a higher activity level and higher consequential wear rate were a difficult group.

The McKee and Ring metal-on-metal total hip replacements were developed in parallel with the metal-onpolyethylene hip. Engineering techniques at the time produced metal-bearing surfaces that were too rough, giving rise to excessive frictional torque that led to a perceived superiority of the Charnley metal-on-plastic implant. However, by the late 1970s and early 1980s, osteolysis, associated with cement and polyethylene fragmentation (historically mis-named "cement disease") resulted in aseptic loosening of longer term implants [8]. Younger, more active patients were particularly affected and the introduction of cementless fixation did not help to solve the problem $[9,10]$.

Aseptic loosening, usually secondary to osteolysis, now attributed to the macrophage response to accumulated polyethylene debris within the joint, remains one of the main causes of failure of major joint arthroplasty. Deep infection and periprosthetic fracture are the other main aetiological factors. Recurrent dislocation of two or more episodes and failure of hip resurfacing secondary to femoral neck fracture or problems related to metal ions are other indications for hip revision. Symptomatic progression of arthritis in the remaining articular portion of a partial knee replacement may indicate the need for revision of a total knee replacement. 


\section{Diagnosis}

Diagnosis of a failed implant requires the exclusion of other causes of pain especially if the implants appear well fixed. Start-up pain, e.g. when getting out of a chair, or pain when going up or down stairs, are the classic symptoms of a loose component. Patients presenting with pain localised to the buttock may have a loose cup and pain localised to the thigh points towards possible loosening of the stem. Infection seeded at the time of the index procedure may be secondary to delayed wound healing, persistent wound "ooze" or superficial cellulitis requiring antibiotics. "Clicking", "popping" or a sensation of the hip moving in and out of the joint may be described by patients with a history of subluxation. The number of overt hip dislocations and the position of the leg at the time of dislocation aid the planning of revision hip surgery. Instability of a total knee replacement may be symptomatic of coronal or sagittal plane imbalance secondary to poor technique at the primary operation or secondary to catastrophic polyethylene wear. Examination of gait, surgical scar, localised tenderness, active and passive range of motion, limb neurology, limb length (when considering the hip) and coronal/sagittal plane stability (when considering the knee) aids diagnosis, surgical planning and guides the post-revision surgery prognosis.

Radiography of the hip ideally includes an anteroposterior (AP) pelvis, a centred AP and a lateral radiograph of the involved hip of sufficient length. Forty-five-degree Judet views provide assessment of the integrity of the anterior and posterior columns [11] that support acetabular reconstruction. It may sometimes be necessary to image the extent of bone loss with computerised tomographic (CT) imaging. Angiography may occasionally be indicated if there is concern that the iliac vessels may be damaged during implant removal. If the vessels lie between the implant and the bone, then a retroperitoneal approach is favoured. An adequate picture of both the distal extent and the distribution of the femoral cement mantle guides the direction of osteotomes, chisels and other cement removal instruments at the time of revision surgery. A good quality lateral is particularly useful. Plain radiography of the knee should include an AP and lateral view of the involved knee demonstrating the complete prosthesis, including any cement, together with full long leg views if there is significant limb deformity. All films should be scrutinised for evidence of loosening, infection (periosteal reaction), bone loss (which is usually underestimated) or significant deformity. CT or magnetic resonance imaging (MRI) can demonstrate cement that does not contain radio-opaque dye and provide a more accurate picture of bone loss [12].

Definite loosening of cemented components exists if there is evidence of component migration, e.g. subsidence of the femoral stem or fracture of the cement mantle; probable loosening exists if there is evidence of a continuous radiolucent line at the bone-cement interface; and possible loosening if there is evidence of a radiolucent line of $50-99 \%$ at the bone-cement interface [13, 14]. Cementless components are unstable if there is evidence of component migration, with subsidence or varus/valgus tilting, or if there is endosteal scalloping around the intramedullary stems; fibrous/stable if there is evidence of reactive lines present in the area of the component's porous coating that are non-progressive and show no evidence of component migration; and osseointegrated if there is an absence of reactive lines in the area of any porous coating or there is presence of spot welds of endosteal new bone contacting the porous surface. For descriptive purposes the acetabular component is divided into three DeLee-Charnley "zones" and the femoral component into seven Gruen "zones" (both numbered from superolateral) on the AP radiograph and seven "zones" on the lateral film $[15,16]$.

There are many classification systems that describe the extent of bone loss around failing components. The ideal classification system should accurately describe the pattern of bone loss from pre-operative images and point towards the most appropriate reconstruction option. It should be reproducible between observers and between repeated observations and allow comparison of different techniques within the published literature [17]. Taking femoral defects around a failed hip implant as an example, the three most common classification systems in current use are:

1. The AAOS classification (D'Antonio et al.) which is descriptive, but less useful for selecting reconstructive options [18, 19]

2. The Mallory classification, which is more simple to use, but does not address more critical determinants of femoral reconstruction [19]

3. The Paprosky classification, which is based on bypassing the compromised proximal femur and is arguably the most useful (Table 1) [20, 21]

Assessment of inter- and intra-observer reliability using any of these classification systems reveals only mild to moderate agreement and often in clinical practice accurate classification of bone loss is finalised at operation. Furthermore, this limited reliability makes comparison of results from different centres difficult [22].

\section{Treatment}

The aims of revision surgery are to extract the failed prosthesis with minimal damage, implant new components to provide long-term stable fixation and manage bone loss by augmenting deficient bone stock. These aims are 
Table 1 The Paprosky classification [20, 21]

\begin{tabular}{ll}
\hline Type & Description \\
\hline I & Minimal loss of metaphyseal cancellous bone with an intact diaphysis \\
II & Extensive loss of metaphyseal cancellous bone with a completely intact diaphysis \\
IIIA & Metaphysis is severely damaged and non-supportive; a minimum of $4 \mathrm{~cm}$ of intact cortical bone is present in the femoral isthmus \\
IIIB & Metaphysis is severely damaged and non-supportive; less than $4 \mathrm{~cm}$ of intact cortical bone present in the femoral isthmus \\
IV & Extensive metaphyseal and diaphyseal damage in conjunction with a widened femoral canal (ectasia) \\
\hline
\end{tabular}

achieved by utilising the original incision where possible, debriding abnormal or infected tissue and removing failed implants together with any associated cement. Exposure of the knee may necessitate a 'rectus snip" or quadriceps turndown (the repair of which would not be evident on post-operative radiographs) or a tibial tubercle osteotomy, which would require screw fixation and introduces the possibility of non-union [23]. A bony femoral window or, specific to the hip, an extended trochanteric osteotomy is occasionally required to remove all foreign material [2325]. The stem of the revision component should bypass any osteotomy by a length equal to two diaphyseal diameters. Osteotomy non-union may compromise the final result. Underlying bone must be cleared of any adherent fibrous membrane before reconstruction can proceed. Reconstruction of deficient bone stock and implantation of new components then proceeds as a single-stage or two-stage procedure (if infection present).

\section{Hip reconstruction}

Acetabular reconstruction utilises either a cemented or an uncemented socket. The bony surface is often sclerotic following removal of failed components, cement and interface membrane. A balance must be struck when reaming this sclerotic bone between fully revealing a healthy bleeding surface and conserving bone stock. Cemented revision components generally require bone graft to improve the quality of fixation at the cement-bone interface as all cancellous bone will have mostly been lost. Mesh can be screwed to existing bone to convert a small segmental defect into a cavitatory defect that allows impaction of morcelised bone graft to recreate bone stock. Structural allograft or trabecular metal wedges can be implanted to reconstruct larger defects.

Cemented, all polyethylene acetabular components have reasonable longevity with impaction grafting of small acetabular defects. Larger defects rely on the press fit or "pinch grip" of an uncemented socket supplemented with multiple screws. The most reliable quadrant for screw placement is the weight-bearing zone posterior to the vertical plane (through the anterior superior iliac spine) bisecting the acetabulum. The porous external surface of the cup is coated with hydroxyapatite that encourages bony ongrowth and ingrowth to achieve a long-term biological fixation. More expensive trabecular metal sockets- the outer surface of which resembles the fine microscopic structure of cancellous bone-can be used in cases of very large bone loss (and are covered in more detail later). Initial fixation and long-term biological fixation are thought to be more stable. Good results can also be achieved by cementing a liner into the acetabular shell when the shell remains well fixed. Pelvic discontinuity, where bone loss has progressed to separate the superior and inferior parts of the pelvis, is an uncommon but difficult management problem that may require supplemental plate fixation or acetabular cage support [26, 27].

Femoral reconstruction utilises either a cemented or an uncemented stem. Cement in cement revision of the femur is appropriate where the cause of the revision is not on the femoral side and the cement-bone interface remains pristine. Bonding of the new cement to the old mantle is good and allows implantation of a smaller sized cemented stem. Specific cemented revision stems have recently come to market for this purpose and the technique has good reported medium-term results [28-30]. When the old cement mantle has failed and requires removal, cemented revision, without supplemental graft, has produced disappointing long-term results: the shear strength of the new cement-bone interface is up to $80 \%$ weaker than in primary THR [31]. Revision with impaction of morcelised bone graft is required to improve the quality of the new cementbone interface and has, in some hands, good proven 10-year results [32-34]. Femoral cortical deficiencies require either reconstruction or must be bypassed by a stem that relies on distal fixation. Where possible, wire is carefully tensioned around a "tube" of mesh to reconstruct the proximal femur, thus again converting a segmental into a cavitatory defect. This allows impaction of autogenous or allogenic morcelised bone graft to augment bone stock. This approach fills very wide or unusually shaped proximal femora, but often requires large amounts of allogenic bone graft. There are reported high rates of implant subsidence (possibly related to inadequate density of initial graft packing) and high rates of peri-prosthetic fracture, which have not been fully resolved by the use of longer stems [35]. 
Reconstruction with a large proximal femoral allograft can be used successfully [36], but integration of a large piece of allogenic bone can be unreliable, donated bone is expensive and supply is limited. If reconstruction of the proximal femur is not possible the defect can be bypassed by an uncemented femoral component that relies on distal fixation [37]. Titanium uncemented stems have a modulus of elasticity or stiffness that is most similar to bone and are considered "bone friendly". Design requires either metaphyseal or diaphyseal fixation, which relies either on directly filling the femoral canal (requiring precise reaming) or on a three-point fixation within the femoral canal. There is a significant risk of cortical perforation or femoral fracture while reaming the deficient cortex. Implantation of uncemented implants is often quicker and more straightforward than impaction grafting and modular stems can ensure the correct stable placement of the femoral head. The modular nature of some stems, however, introduces another mechanical interface, which can potentially fail.

In the presence of massive bone loss a large proximal femoral replacing prosthesis can be used [38, 39]. These "megaprostheses", or tumour prostheses, are more suitable in elderly sedentary patients. Abductor mechanism failure and a high rate of dislocation are the main disadvantages.

\section{Knee reconstruction}

The choice of implant is dictated by the extent of bone and soft tissue destruction following the removal of failed implants. There is a spectrum of implants available from posterior cruciate ligament (PCL) sparing resurfacing implants to "mega-", tumour- or bone-replacing prostheses.

The level of built-in constraint required in revision knee prostheses depends upon whether the posterior cruciate and collateral ligaments are preserved. PCL sparing/preserving resurfacing components can be used if removal of failed implants results in a knee that compares favourably to a primary TKR with intact ligaments. If the PCL is compromised or there is a fixed coronal plane or flexion deformity the PCL is substituted by a cam and post, the design of which controls sagittal plane kinematics. This subtly changes the projected shadow of the femoral implant on the AP radiograph. The height and width of the post on the polyethylene insert can be increased to provide increased varus/valgus stability. If the collateral ligaments are compromised a hinged prosthesis is chosen to further improve coronal plane stability. Inevitably, this puts greater strain upon the hinge itself and produces increased shear stress at the implant interface with the bone. A rotating hinge allows movement in the axial plane between the polyethylene and the tibial surface, decreasing these stresses, but producing a secondary surface for the generation of wear debris. Modular femoral and tibial stems are added to the resurfacing implants in this scenario to increase the area of fixation, spreading load and decreasing stresses at the implant-bone interface.

Femoral or tibial stems of varying lengths may also be added if there are significant uncontained bone defects. Generally, a contained bony defect with an intact cortical rim or an uncontained defect of less than $5 \mathrm{~mm}$ can be filled with cement upon implantation. Contained defects greater than $5 \mathrm{~mm}$ with an intact cortical rim can be treated with morcelised impaction grafting in a similar manner to the hip. Uncontained defects require shaping to accommodate metal wedges that are added to the implant. Larger defects may require bulk allograft. The addition of a femoral or tibial stem provides additional stability and protects supplemented defects, minimising the risk of long-term implant subsidence [40].

Distal femoral or proximal tibial replacing hinged "megaprostheses" are utilised if there is massive bone loss and these function well in low-demand patients.

\section{The future}

Incremental improvements in implant engineering, design and material science continue to promise improvements in the fixation of implants to bone, which will hopefully lead to improvements in the longevity of both primary and revision implants. For example, new porous "bone friendly" titanium (Ti) and tantalum (Ta) implants were introduced in the late 1990s. Tantalum is a very hard, dense, ductile, easily fabricated transition metal with a good biocompatibility and safety record. Vapour deposition of commercially pure elemental tantalum onto a polymer foam skeleton creates a trabecular metallic (TM) configuration of high porosity with physical and mechanical properties similar to bone, i.e. a low stiffness ( $3 \mathrm{GPa}$ ), but a yield and ultimate strength that are ten times greater than those of subchondral bone [41-44]. Early clinical and radiological results are encouraging [41, 45-48], but time will tell if the additional cost of these new materials leads to sufficient additional clinical benefit.

The debate regarding the optimal bearing surface also continues to evolve. Pathological processes that disrupt the implant-bone interface are minimised by reducing wear of the bearing surface or moving parts. As previously discussed, osteolysis was noted to be a significant problem in the late 1970s and early 1980s in longer term implants. Attention has thus, over the last decade or so, turned to socalled hard-on-hard bearing surfaces. A proportion of the original McKee and Ring metal-on-metal cobalt chrome hips were found to be long-lasting and retained their mirrorlike articulating finish [49]. These successful implants had achieved an exacting, highly polar bearing geometry at 
manufacture that can now, with modern engineering techniques, be consistently reproduced. Similar tolerances can also nowadays be achieved with ceramic-on-ceramic implants. In vitro wear tests reveal 10 to 100 times lower rates than traditional polyethylene and medium term results are promising [50-58]. There are, however, potential down sides: a $2 \%$ risk of "squeaking" and a small but serious risk of implant fracture with the ceramic hip; plus, a small but serious risk of problems related to high metal ions with the metal-on-metal hip that has only recently revealed itself [59-62].

These concerns, taken together with the improved wear characteristics of new "ultra-highly crosslinked" polyethylene and new vitamin-impregnated polyethylenes, have led to the pendulum swinging back in favour of an improved traditional metal-on-polyethylene bearing surface. Improved polyethylene may also allow larger bearing surface diameters to be employed, resulting in greater stability than that afforded by Charnley's original small-diameter, lowfriction arthroplasty. As ever though, the long-term clinical and radiological results of these new materials are eagerly awaited.

\section{References}

1. The Norwegian Arthroplasty Register Report 2006: www. haukeland.no/nrl/eng. 2006.

2. The Swedish Hip Arthroplasty Register Annual Report 2006: www.jru.orthop.gu.se. 2006.

3. The Australian National Joint Replacement Registry Annual Report 2008: www.dmac.adelaide.edu.au/aoanjrr. 2008.

4. Charnley J. Using teflon in arthroplasty of the hip-joint. J Bone Jt Surg Am. 1966;48:819.

5. Charnley J. Arthroplasty of the hip. A new operation. Lancet. 1961;27(1):1129-32.

6. Charnley JF, Kamangar AF, Longfield MD. The optimum size of prosthetic heads in relation to the wear of plastic sockets in total replacement of the hip. Med Biol Eng. 1969;7:31-9.

7. Charnley J. Total hip replacement by low-friction arthroplasty. Clin Orthop Relat Res. 1970;72:7-21.

8. Willert HG, Bertram HF, Buchhorn GH. Osteolysis in alloarthroplasty of the hip. The role of ultra-high molecular weight polyethylene wear particles. Clin Orthop Relat Res. 1990;258:95-107.

9. Schmalzried TP, Shepherd EF, Dorey FJ, Jackson WO, dela Rosa MF, Fa'vae FF, et al. The John Charnley Award. Wear is a function of use, not time. Clin Orthop Relat Res. 2000;381:36-46.

10. Schmalzried TP, Jasty MF, Harris WH. Periprosthetic bone loss in total hip arthroplasty. Polyethylene wear debris and the concept of the effective joint space. J Bone Jt Surg Am. 1992;74:849-63.

11. Judet RF, Judet JF, Letournel E. Fractures of the acetabulum: classification and surgical approaches for open reduction. J Bone Jt Surg Am. 1964;46:1615-46.

12. Fehrman DF, McBeath AA, DeSmet AA, Tuite MJ. Imaging barium-free bone cement. Am J Orthop. 1996;25:172-4.

13. Harris WH, McCarthy JC Jr, O’Neill DA. Femoral component loosening using contemporary techniques of femoral cement fixation. J Bone Jt Surg Am. 1982;64:1063-7.
14. Johnston RC, Fitzgerald RH Jr, Harris WH, Poss RF, Muller ME, Sledge CB. Clinical and radiographic evaluation of total hip replacement. A standard system of terminology for reporting results. J Bone Jt Surg Am. 1990;72:161-8.

15. DeLee JG, Charnley J. Radiological demarcation of cemented sockets in total hip replacement. Clin Orthop Relat Res. 1976;121:20-32.

16. Gruen TA, McNeice GM, Amstutz HC. "Modes of failure" of cemented stem-type femoral components: a radiographic analysis of loosening. Clin Orthop Relat Res. 1979;141:17-27.

17. Masri BA, Masterson EF, Duncan CP. The classification and radiographic evaluation of bone loss in revision hip arthroplasty. Orthop Clin North Am. 1998;29:219-27.

18. D'Antonio JF, McCarthy JC, Bargar WL, Borden LS, Cappelo WN, Collis DK, et al. Classification of femoral abnormalities in total hip arthroplasty. Clin Orthop Relat Res. 1993;296:133-9.

19. Mallory TH. Preparation of the proximal femur in cementless total hip revision. Clin Orthop Relat Res. 1988;235:47-60.

20. Della Valle CJ, Paprosky WG. The femur in revision total hip arthroplasty evaluation and classification. Clin Orthop Relat Res. 2004;420:55-62.

21. Paprosky WG, Burnett RS. Assessment and classification of bone stock deficiency in revision total hip arthroplasty. Am J Orthop. 2002;31:459-64.

22. Haddad FS, Masri BA, Garbuz DS, Duncan CP. Femoral bone loss in total hip arthroplasty: classification and preoperative planning. Instr Course Lect. 2000;49:83-96.

23. Masri BA, Campbell DG, Garbuz DS, Duncan CP. Seven specialized exposures for revision hip and knee replacement. Orthop Clin North Am. 1998;29:229-40.

24. Della Valle C, Berger RA, Rosenberg AG, Jacobs JJ, Sheinkop MB, Paprosky WG. Extended trochanteric osteotomy in complex primary total hip arthroplasty. A brief note. J Bone Jt Surg Am. 2003;85-A:2385-90.

25. Meek RM, Greidanus NV, Garbuz DS, Masri BA, Duncan CP. Extended trochanteric osteotomy: planning, surgical technique, and pitfalls. Instr Course Lect. 2004;53:119-30.

26. Berry DJ, Lewallen DG, Hanssen AD, Cabanela ME. Pelvic discontinuity in revision total hip arthroplasty. J Bone Jt Surg Am. 1999;81:1692-702.

27. Berry DJ. Identification and management of pelvic discontinuity. Orthopedics. 2001;24:881-2.

28. Goto KF, Kawanabe KF, Akiyama HF, Morimoto TF, Nakamura T. Clinical and radiological evaluation of revision hip arthroplasty using the cement-in-cement technique. J Bone Jt Surg Br. 2008;90:1013-8.

29. Quinlan JF, O'Shea KF, Doyle FF, Brady OH. In-cement technique for revision hip arthroplasty. J Bone Jt Surg Br. 2006;88:730-3.

30. Lieberman JR, Moeckel BH, Evans BG, Salvati EA, Ranawat CS. Cement-within-cement revision hip arthroplasty. J Bone Jt Surg Br. 1993;75:869-71.

31. Rosenstein AF, MacDonald WF, Iliadis AF, McLardy-Smith P. Revision of cemented fixation and cement-bone interface strength. Proc Inst Mech Eng [H]. 1992;206:47-9.

32. Halliday BR, English HW, Timperley AJ, Gie GA, Ling RS. Femoral impaction grafting with cement in revision total hip replacement. Evolution of the technique and results. J Bone Jt Surg Br. 2003;85:809-17.

33. Duncan CP, Masterson EF, Masri BA. Impaction allografting with cement for the management of femoral bone loss. Orthop Clin North Am. 1998;29:297-305.

34. Wraighte PJ, Howard PW. Femoral impaction bone allografting with an Exeter cemented collarless, polished, tapered stem in revision hip replacement: a mean follow-up of 10.5 years. J Bone Jt Surg Br. 2008;90:1000-4. 
35. Sierra RJ, Charity JF, Tsiridis E, Timperley JA, Gie GA. The use of long cemented stems for femoral impaction grafting in revision total hip arthroplasty. J Bone Jt Surg Br. 2008;90:1330-6.

36. Safir OF, Kellett CF, Flint MF, Backstein DF, Gross AE. Revision of the deficient proximal femur with a proximal femoral allograft. Clin Orthop Relat Res. 2009;467:206-12.

37. Bohm PF, Bischel O. Femoral revision with the Wagner SL revision stem: evaluation of one hundred and twenty-nine revisions followed for a mean of 4.8 years. J Bone Jt Surg Am. 2001;83-A:1023-31.

38. Malkani AF, Paiso JM, Sim FH. Proximal femoral replacement with megaprosthesis. Instr Course Lect. 2000;49:141-6.

39. Zehr RJ, Enneking WF, Scarborough MT. Allograft-prosthesis composite versus megaprosthesis in proximal femoral reconstruction. Clin Orthop Relat Res. 1996;322:207-23.

40. Whittaker JP, Dharmarajan RF, Toms AD. The management of bone loss in revision total knee replacement. J Bone Jt Surg Br. 2008;90:981-7.

41. Levine BR, Sporer S, Poggie RA, Della Valle CJ, Jacobs JJ. Experimental and clinical performance of porous tantalum in orthopedic surgery. Biomaterials. 2006;27:4671-81.

42. Bobyn JD, Stackpool GJ, Hacking SA, Tanzer MF, Krygier JJ. Characteristics of bone ingrowth and interface mechanics of a new porous tantalum biomaterial. J Bone Jt Surg Br. 1999;81:907-14.

43. Bobyn JD, Toh KK, Hacking SA, Tanzer MF, Krygier JJ. Tissue response to porous tantalum acetabular cups: a canine model. J Arthroplasty. 1999;14:347-54.

44. Hacking SA, Bobyn JD, Toh KF, Tanzer MF, Krygier JJ. Fibrous tissue ingrowth and attachment to porous tantalum. J Biomed Mater Res. 2000;52:631-8.

45. Meneghini RM, Lewallen DG, Hanssen AD. Use of porous tantalum metaphyseal cones for severe tibial bone loss during revision total knee replacement. Surgical technique. J Bone Jt Surg Am. 2009;91(Suppl 2 Pt 1):131-8.

46. Levine BF, Sporer S, Della Valle CJ, Jacobs JJ, Paprosky W. Porous tantalum in reconstructive surgery of the knee: a review. $\mathrm{J}$ Knee Surg. 2007;20:185-94.

47. Long WJ, Scuderi GR. Porous tantalum cones for large metaphyseal tibial defects in revision total knee arthroplasty a minimum 2-year follow-up. J Arthroplasty. 2008; doi:10.1016/j. arth.2008.08.011.

48. Macheras GA, Papagelopoulos PJ, Kateros KF, Kostakos AT, Baltas DF, Karachalios TS. Radiological evaluation of the metalbone interface of a porous tantalum monoblock acetabular component. J Bone Jt Surg Br. 2006;88:304-9.
49. Jacobsson SA, Djerf KF, Wahlstrom O. Twenty-year results of McKee-Farrar versus Charnley prosthesis. Clin Orthop Relat Res. 1996;329 (Suppl):S60-8.

50. Rieker CB, Schon RF, Kottig P. Development and validation of a second-generation metal-on-metal bearing: laboratory studies and analysis of retrievals. J Arthroplasty. 2004;19:5-11.

51. Chan FW, Bobyn JD, Medley JB, Krygier JJ, Yue S, Tanzer M. Engineering issues and wear performance of metal on metal hip implants. Clin Orthop Relat Res. 1996;333:96-107.

52. Chan FW, Bobyn JD, Medley JB, Krygier JJ, Tanzer M. The Otto Aufranc Award. Wear and lubrication of metal-on-metal hip implants. Clin Orthop Relat Res. 1999;369:10-24.

53. Long WT, Dorr LD, Gendelman V. An American experience with metal-on-metal total hip arthroplasties: a 7-year follow-up study. J Arthroplasty. 2004;19:29-34.

54. Back DL, Dalziel R, Young D, Shimmin A. Early results of primary Birmingham hip resurfacings: an independent prospective study of the first 230 hips. J Bone Jt Surg Br. 2005;87-B:324-9.

55. Delaunay CP. Metal-on-metal bearings in cementless primary total hip arthroplasty. J Arthroplasty. 2004;19:35-40.

56. Eswaramoorthy V, Moonot P, Kalairajah Y, Biant LC, Field RE. The Metasul metal-on-metal articulation in primary total hip replacement: clinical and radiological results at ten years. J Bone Jt Surg Br. 2008;90-B:1278-83.

57. Steffen RT, Pandit HP, Palan J, Beard DJ, Gundle R, McLardySmith P, et al. The five-year results of the Birmingham Hip Resurfacing arthroplasty: an independent series. J Bone Jt Surg Br. 2008;90-B:436-41.

58. Treacy RBC, McBryde CW, Pynsent PB. Birmingham hip resurfacing arthroplasty: a minimum follow up of five years. J Bone Jt Surg Br. 2005;87-B:167-70.

59. Gruber FW, Bock AF, Trattnig S, Lintner FF, Ritschl P. Cystic lesion of the groin due to metallosis: a rare long-term complication of metal-on-metal total hip arthroplasty. J Arthroplasty. 2007;22:923-7.

60. Boardman DR, Middleton FR, Kavanagh TG. A benign psoas mass following metal-on-metal resurfacing of the hip. J Bone Jt Surg Br. 2006;88-B:402-4.

61. Pandit H, Glyn-Jones S, McLardy-Smith P, Gundle R, Whitwell D, Gibbons CLM, et al Pseudotumours associated with metal-onmetal hip resurfacings. J Bone Jt Surg Br. 2008;90-B:847-51.

62. Pandit H, Vlychou M, Whitwell D, Crook D, Luqmani R, Ostlere $\mathrm{S}$, et al. Necrotic granulomatous pseudotumours in bilateral resurfacing hip arthroplasties: evidence for a type IV immune response. Virchows Arch. 2008;453:529-34. 